\title{
Analisis Efektivias Commuter Line Ticket Vending Machine (C-VIM) terhadap Penanganan Antrian Pembelian Tiket di Stasiun Bekasi.
}

\author{
Yudhia Rahma* \\ Program Studi Administrasi Bisnis Terapan, Politeknik Negeri Jakarta \\ Jalan Prof. Dr. G.A. Siwabessy, Kampus Universitas Indonesia, Depok, Indonesia \\ yudhiarahma@gmail.com
}

Iis Mariam

Program Studi Administrasi Bisnis Terapan, Politeknik Negeri Jakarta

Jalan Prof. Dr. G.A. Siwabessy, Kampus Universitas Indonesia, Depok, Indonesia

Iis.mariam@bisnis.pnj.ac.id

\begin{tabular}{l|l|l} 
Diterima: 03-09-2020 | Disetujui: 07-07-2021 | Dipublikasi: 31-07-2021
\end{tabular}

\begin{abstract}
(c)
ABSTRAK

PT KCI berinovasi mengeluarkan pelayanan terbarunya yaitu Commuter Line Ticket Vending Machine (C-VIM). Inovasi ini ditujukan untuk menjawab keluhan pelanggan tentang lamanya waktu yang dihabiskan untuk mengantri tiket di loket. C-VIM merupakan bentuk inovasi pelayanan PT KCI dengan tujuan mengurai antrian yang terjadi pada loket konvensional. Penelitian ini bertujuan untuk mengetahui dan menganalisis bagaimana efektivitas pelayanan C-VIM dalam menangani antrian pembelian tiket. Penelitian dilakukan di stasiun Bekasi sebagai stasiun dengan jumlah penumpang terbanyak pada 2019. Penelitian menggunakan pendekatan kuantitatif dengan membagikan kuesioner kepada 100 responden pengguna C-VIM. Teknik analisis data yang digunakan dalam penelitian ini terbagi dalam tiga tahap, yaitu: uji instrumen, uji asumsi klasik, dan uji hipotesis. Uji instrument ditujukan untuk menganalisis uji validitas dan uji reliabilitas. Uji asumsi klasik terdiri dari uji normalitas dan uji linearitas. Uji hipotesis terdiri dari analisis regresi linear sederhana, analisis korelasi sederhana, koefisien determinasi, dan uji signifikan T. Hasil analisis data yang diperoleh menunjukkan adanya pengaruh secara signifikan dan positif, sehingga dapat dikatakan bahwa adanya pengaruh efektivitas pelayanan C-VIM dalam menangani antrian pembelian tiket di Stasiun Bekasi, sehingga, C-VIM efektif untuk terus digunakan dalam upaya peningkatan pelayanan PT KCI dengan diharapkan terjadinya beberapa perbaikan di masa mendatang.
\end{abstract}

Kata Kunci:

Commuter Line Ticket Vending Machine (C-VIM); Efektivitas; Pelayanan.

\begin{abstract}
PT KCI innovated the newest service, namely the Commuter Line Ticket Vending Machine (C-VIM). This innovation is intended to answer customer complaints about the time spent queuing for tickets at the counter. $C$ VIM is a machine of PT KCI service innovation with the aim of parsing the queues that occur at conventional counters. This study aims to determine and analyze how the effectiveness of C-VIM services in handling ticket purchase queues. The research was conducted at Bekasi station as the station with the highest number of passengers in 2019. The study used a quantitative approach by distributing questionnaires to 100 respondents who were C-VIM users. The data analysis technique used in this study is divided into three stages, namely: instrument test, classical assumption test, and hypothesis testing. The instrument test is intended to analyze the validity and reliability tests. The classical assumption test consists of a normality test and a linearity test. Hypothesis testing consists of simple linear regression analysis, simple correlation analysis, coefficient of determination, and significant $T$ test. The results of the data analysis obtained show a significant and positive effect, so it can be said that there is an effect of the effectiveness of C-VIM services in handling ticket purchase queues. at Bekasi Station, therefore, C-VIM is effective to continue to be used in the efforts to improve PT KCI services with the hope that some improvements will occur in the future
\end{abstract}

Keywords:

Commuter Line Ticketing Machine (C-VIM); Effectiveness; Service 


\section{PENDAHULUAN}

Jakarta, sebagai pusat bisnis di Indonesia menjadi salah satu kota dengan total mobilitas tertinggi setiap harinya. Hal ini diikuti dengan kota-kota besar di sekitarnya seperti Bogor, Depok, Tangerang, dan Bekasi. Berdasarkan data angka pekerja di Jakarta sudah mencapai 5.157.878 (Badan Pusat Statistik, 2019). Meningkatnya angka pekerja ini, tentu perlu diimbangi dengan kesiapan pemerintah dalam menyediakan kebutuhan masyarakat akan moda transportasi. Permasalahan umum transportasi adalah bagaimana memindahkan orang dari satu tempat ke tempat tertentu dengan biaya paling rendah. Masyarakat membutuhkan transportasi massal yang efektif dan efisien guna menunjang aktivitas sehari-hari.

Menurut Ravianto dalam Masruri (2014) pengertian efektivitas ialah seberapa baik pekerjaan yang dilakukan, sejauh mana orang menghasilkan keluaran sesuai dengan yang diharapkan. Efektivitas menurut Umam (2012) memiliki empat faktor mempengaruhi, yaitu karakteristik organisasi, karakteristik lingkungan, karakteristik pekerja, dan karakteristik manajemen. Berdasarkan hal tersebut, masyarakat Jakarta membutuhkan transportasi dengan biaya rendah namun dapat memenuhi kebutuhan akan kenyamanan, keamanan, dan kecepatan pengguna. Menangani kondisi tersebut, pemerintah menyediakan beberapa alternatif transportasi yang dioperasikan khusus pada kota-kota besar Jabodetabek seperti bus Transjakarta, kereta Commuter Line, LRT, maupun MRT. Salah satu moda transportasi dengan minat konsumen tertinggi yaitu kereta Commuter Line.

Menurut Direktur Utama PT KCI Widayanti (2019), angka jumlah penumpang Commuter Line mencapai 916.799 orang per hari. Tingginya angka pengguna setiap hari, menyebabkan beberapa permasalahan dalam pelayanan. Salah satu permasalahan pelayanan adalah dalam hal penanganan pembelian tiket. Pelayanan menurut Sinambela (2011) pelayanan adalah suatu kegiatan atau urutan kegiatan yang terjadi dalam interaksi langsung antara seseorang dengan orang lain atau mesin secara fisik, dan menyediakan kepuasan pelanggan antrian pada loket pembelian tiket. Melihat kondisi tersebut, PT KCI berupaya memenuhi kepuasan pelanggan dengan terus meningkatkan pelayanan. Pada 27 Desember 2015 PT KCI mengeluarkan inovasi baru dalam perihal pembelian tiket yaitu Commuter Vending Machine (C-VIM) dengan sistem Self Service. Commuter Vending Machine (C-VIM) merupakan fasilitas yang disediakan PT KCI sebagai salah satu alternatif pembelian tiket selain loket konvensional sehingga diharapkan dapat mempercepat proses pembelian tiket dan dapat mengurai antrian yang terjadi di loket konvensional.

Direktur Utama PT KCI Widayanti (2019), menjelaskan urutan penumpang terbanyak pada 2019 yaitu stasiun Bogor dengan jumlah penumpang hingga 19 juta orang. Stasiun Tanah Abang dengan angka 15,02 juta orang, kemudian stasiun Bekasi dengan jumlah penumpang 14,8 juta orang. Stasiun Bekasi merupakan stasiun dengan jumlah pengguna Commuter Line terbanyak ketiga. Ketiga stasiun yang tersebut telah menerapkan fasilitas Commuter Vending Machine (C-VIM) dengan rincian stasiun Bogor memiliki 17 unit, stasiun Tanah Abang dengan 4 unit, dan stasiun Bekasi memiliki 3 unit. 
Melihat dari data yang ada, peneliti tertarik untuk melakukan penelitian di Stasiun Bekasi karena stasiun Bekasi merupakan stasiun dengan jumlah penumpang terbanyak ketiga, dengan hanya menyediakan 3 unit C-VIM. Hal ini dapat memicu masalah karena jumlah penumpang tidak sebanding dengan jumlah fasilitas yang disediakan. Penelitian ini bertujuan untuk mengetahui dan menganalisis bagaimana efektivitas penggunaan C-VIM yang diterapkan di stasiun Bekasi sebagai salah satu stasiun dengan jumlah penumpang terbanyak pada 2019.

Berdasarkan uraian latar belakang di atas, peneliti tertarik untuk mengetahui dan melakukan penelitian terkait Commuter Vending Machine (C-VIM) yang berada di stasiun Bekasi dengan judul Analisis Efektivitas Commuter Line Ticket Vending Machine (C-VIM) dalam menangani antrian pembelian tiket di stasiun Bekasi.

\section{Tujuan}

C-VIM sebagai bentuk inovasi PT KCI tentu bukan dioperasikan tanpa tujuan. C-VIM diharapkan mampu menjawab keluhan pelanggan terhadap panjangnya antrian pembelian tiket di loket konvensional. Hal ini berkaitan dengan tujuan penelitian ini yaitu untuk mengetahui dan menganalisis seberapa efektif penggunaan C-VIM dalam menangani antrian pembelian tiket di Stasiun Bekasi.

\section{Permasalahan}

Rumusan masalah pada penelitian ini yaitu Apakah tujuan PT KCI mengeluarkan Commuter Line Ticket Vending Machine (C-VIM) sudah sesuai dengan kebutuhan konsumen dan seberapa efektif penggunaan Commuter Line Ticket Vending Machine (C-VIM) dalam menangani antrian pembelian tiket di stasiun Bekasi?

\section{METODE RISET}

Variabel yang digunakan terdiri dari satu variabel bebas (X) dan satu variabel terikat (Y). Variabel bebas dalam penelitian ini yaitu efektivitas pelayanan, sementara variabel terikat dalam penelitian ini yaitu antrian pembelian tiket. Tempat yang dipilih dalam penelitian ini yaitu stasiun Bekasi. Penelitian dilakukan selama 5 bulan, dimulai dari bulan Maret hingga bulan Juli 2020.

Metode penelitian menggunakan pendekatan kuantitatif dengan melakukan penyebaran kuesioner kepada 100 orang responden di stasiun Bekasi dengan memperhatikan kemungkinan kondisi saat ini. Analisis data terdiri dari uji instrumen, uji asumsi klasik, dan uji hipotesis. Populasi yang digunakan dalam penelitian ini adalah penumpang KRL commuter line di stasiun Bekasi. Teknik pengambilan sampel dilakukan dengan teknik non probability sampling dengan membagikan kuesioner tanpa melakukan pembedaan pada populasi.

Tahapan pengolahan data pada penelitian ini terdiri dari empat tahap, yaitu:

1. Validasi Data

2. Editing dan Coding

3. Data Entry 
4. Tabulasi Data

Berdasarkan tujuan dari penelitian ini, maka teknik analisis data yang dipilih terdiri dari tiga tahap yaitu Uji Instrumen, Uji Asumsi Klasik, dan Uji Hipotesis. Uji instrumen dilakukan untuk menguji seberapa layak instrumen untuk digunakan dalam penelitian. Uji instrumen terdiri dalam dua tahap, yaitu:

1. Uji Validitas

2. Uji Reliabilitas

Uji asumsi klasik terdiri dari dua tahap, yaitu:

1. Uji Normalitas

2. Uji Linearitas

Uji hipotesis digunakan untuk menentukan apakah hipotesis diterima atau ditolak. Uji hipotesis penelitian ini terdiri dari empat tahap, yaitu:

1. Regresi linear sederhana

2. Analisis korelasi sederhana

3. Koefisien determinasi

4. Uji signifikan $\mathrm{T}$

\section{HASIL PENELITIAN DAN PEMBAHASAN}

\section{Hasil Penelitian}

Penelitian didahului dengan melakukan uji instrumen. Uji instrumen digunakan untuk mengukur apakah butir-butir instrumen layak digunakan dalam penelitian. Tahapan uji instrumen dijelaskan pada tabel berikut:

Hasil uji reliabilitas dijelaskan pada tabel berikut:

Tabel 1. Uji Reliabilitas

\begin{tabular}{ccccc}
\hline \multirow{2}{*}{ No } & Variabel & $\begin{array}{c}\text { Cronbach's } \\
\text { Alpha }\end{array}$ & N of Items & Information \\
\hline 1 & Efektivitas Pelayanan & 0,730 & 24 & Reliable \\
2 & Antrian & 0,755 & 22 & Reliable \\
& Responden & & 10 &
\end{tabular}

Hasil Cronbach's Alpha kedua variabel lebih besar dari 0,70. Berdasarkan metode Cronbach's Alpha, disimpulkan kedua variabel pada penelitian ini sudah reliabel. Hasil uji validitas dapat dijelaskan pada tabel 3. Berdasarkan hasil tabel tersebut, maka butir pertanyaan 5 untuk variabel $X$ dan pertanyaan 4,13, dan 25 untuk variabel Y harus dihapus dan tidak dipergunakan lagi.

Hasil analisis data dilanjutkan dengan uji asumsi klasik yaitu uji normalitas dan uji linearitas. Hasil uji normalitas dan linearitas disajikan dalam tabel berikut: 
Rahma, Y. \& Mariam, I.(2021). Analisis Efektivitas Commuter Line Ticket Vending Machine ....

Tabel 2. Uji Normalitas

One-Sample Kolmogorov-Smirnov Test

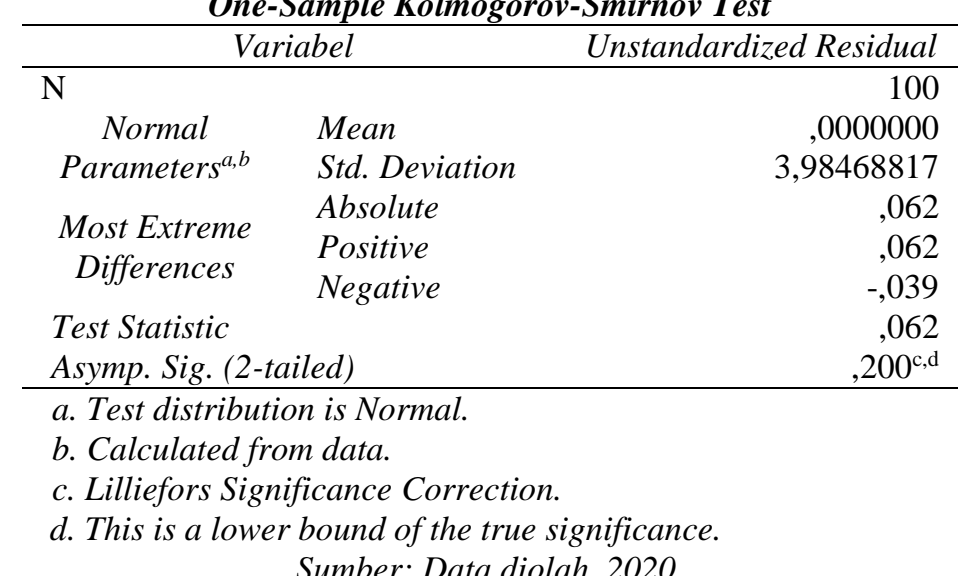

Sumber: Data diolah, 2020

Hasil tes Kolmogorov-Smirnov memiliki nilai lebih besar dari 0,05, sehingga disimpulkan normalitas Kolmogorov-Smirnov berdistribusi normal

Tabel 3. Uji Validitas

\begin{tabular}{ccccccc}
\hline \multirow{2}{*}{ Pertanyaan } & \multicolumn{2}{c}{ Variabel X (Efektivitas Pelayanan) } & \multicolumn{3}{c}{ Variabel Y (Antrian) } \\
\cline { 2 - 6 } & R hitung & r Tabel & Keterangan & R hitung & r Tabel & Keterangan \\
\hline Pertanyaan 1 & 0,893 & 0,5494 & Valid & 728 & 0,5494 & Valid \\
Pertanyaan 2 & 0,772 & 0,5494 & Valid & 746 & 0,5494 & Valid \\
Pertanyaan 3 & 0,780 & 0,5494 & Valid &, 746 & 0,5494 & Valid \\
Pertanyaan 4 & 0,669 & 0,5494 & Valid &, 251 & 0,5494 & Tidak Valid \\
Pertanyaan 5 & 0,412 & 0,5494 & Tidak Valid &, 731 & 0,5494 & Valid \\
Pertanyaan 6 & 0,636 & 0,5494 & Valid &, 826 & 0,5494 & Valid \\
Pertanyaan 7 & 0,745 & 0,5494 & Valid &, 691 & 0,5494 & Valid \\
Pertanyaan 8 & 0,752 & 0,5494 & Valid & 767 & 0,5494 & Valid \\
Pertanyaan 9 & 0,875 & 0,5494 & Valid &, 756 & 0,5494 & Valid \\
Pertanyaan 10 & 0,735 & 0,5494 & Valid &, 670 & 0,5494 & Valid \\
Pertanyaan 11 & 0,800 & 0,5494 & Valid &, 765 & 0,5494 & Valid \\
Pertanyaan 12 & 0,720 & 0,5494 & Valid &, 765 & 0,5494 & Valid \\
Pertanyaan 13 & 0,802 & 0,5494 & Valid &, 338 & 0,5494 & Tidak Valid \\
Pertanyaan 14 & 0,879 & 0,5494 & Valid &, 768 & 0,5494 & Valid \\
Pertanyaan 15 & 0,879 & 0,5494 & Valid &, 755 & 0,5494 & Valid \\
Pertanyaan 16 & 0,711 & 0,5494 & Valid &, 666 & 0,5494 & Valid \\
Pertanyaan 17 & 0,632 & 0,5494 & Valid &, 645 & 0,5494 & Valid \\
Pertanyaan 18 & 0,836 & 0,5494 & Valid &, 733 & 0,5494 & Valid \\
Pertanyaan 19 & 0,869 & 0,5494 & Valid &, 709 & 0,5494 & Valid \\
Pertanyaan 20 & 0,715 & 0,5494 & Valid &, 843 & 0,5494 & Valid \\
Pertanyaan 21 & 0,635 & 0,5494 & Valid &, 686 & 0,5494 & Valid \\
Pertanyaan 22 & 0,759 & 0,5494 & Valid &, 679 & 0,5494 & Valid \\
Pertanyaan 23 & 0,887 & 0,5494 & Valid &, 800 & 0,5494 & Valid \\
Pertanyaan 24 & 0,667 & 0,5494 & Valid &, 800 & 0,5494 & Valid \\
Pertanyaan 25 & 0,726 & 0,5494 & Valid &, 522 & 0,5494 & Tidak Valid \\
\hline
\end{tabular}

Sumber: Data diolah, 2020

Hasil uji linearitas disajikan dalam tabel 4. Hasil uji linearitas, menunjukkan nilai Sig Deviation from Linearity lebih besar daripada 0,05, maka disimpulkan bahwa antara variabel $\mathrm{X}$ dan variabel $\mathrm{Y}$ memiliki hubungan yang linear. 


\begin{tabular}{|c|c|c|c|c|c|c|c|}
\hline \multicolumn{8}{|c|}{ Tabel 4. Uji Linearitas } \\
\hline & & & Sum of Squares & $D f$ & Mean Square & $F$ & Sig. \\
\hline TOTALY * & Between & (Combined) & 1067,697 & 24 & 44,487 & 3,094 & 000 \\
\hline \multirow[t]{4}{*}{ TOTALX } & Groups & Linearity & 574,104 & 1 & 574,104 & 39,931 & 000 \\
\hline & & $\begin{array}{l}\text { Deviation } \\
\text { from } \\
\text { Linearity }\end{array}$ & 493,593 & 23 & 21,461 & 1,493 &, 100 \\
\hline & Within & oups & 1078,303 & 75 & 14,377 & & \\
\hline & Total & & 2146,000 & 99 & & & \\
\hline
\end{tabular}

Sumber: Data diolah, 2020

Setelah mengetahui hasil linearitas, uji selanjutnya adalah regresi linear sederhana yang disajikan pada tabel berikut:

Tabel 5. Regresi Linear Sederhana

ANOVA ${ }^{\mathrm{a}}$

\begin{tabular}{llrrrrr}
\hline Model & & Sum of Squares & Df & Mean Square & $F$ & Sig. \\
\hline 1 & Regression & 574,104 & 1 & 574,104 & 35,793 &, $000^{\mathrm{b}}$ \\
& Residual & 1571,896 & 98 & 16,040 & & \\
& Total & 2146,000 & 99 & & & \\
&
\end{tabular}

a. Dependent Variable: TOTALLY

b. Predictors: (Constant), TOTALX

Sumber: Data diolah, 2020

F hitung pada analisis regresi linear sederhana menunjukkan nilai lebih besar dari F Tabel sebesar 3.94, hal ini berarti terdapat hubungan antara kedua variabel. Signifikansi kedua variabel menunjukkan angka 0,000. Hasil ini lebih kecil dari 0,05, maka dapat disimpulkan bahwa variabel X berpengaruh terhadap variabel $\mathrm{Y}$.

Hasil analisis korelasi sederhana digunakan untuk menentukan tingkat hubungan antar variabel.

Tabel 6. Analisis Korelasi Sederhana

\begin{tabular}{|c|c|c|c|}
\hline \multicolumn{4}{|c|}{ Correlations } \\
\hline & & TOTALX & TOTALLY \\
\hline \multirow[t]{3}{*}{ TOTALX } & Pearson Correlation & 1 &, $517^{* *}$ \\
\hline & Sig. (2-tailed) & &, 000 \\
\hline & $N$ & 100 & 100 \\
\hline \multirow[t]{3}{*}{ TOTALLY } & Pearson Correlation &, $517^{* *}$ & 1 \\
\hline & Sig. (2-tailed) & ,000 & \\
\hline & $N$ & 100 & 100 \\
\hline
\end{tabular}

Berdasarkan hasil pengolahan data, nilai Pearson Correlation menunjukkan angka 0,517. Jika diinterpretasikan ke dalam tabel koefisien korelasi, hubungan antara variabel $\mathrm{X}$ dengan variabel $\mathrm{Y}$ memiliki tingkat hubungan sedang.

Hasil koefisien determinasi disajikan pada tabel berikut:

\section{Tabel 7. Koefisien Determinasi} Model Summary ${ }^{b}$

\begin{tabular}{llccr}
\multicolumn{5}{c}{ Model Summary $^{b}$} \\
\hline Model & $R$ & $R$ Square & Adjusted $R$ Square & Std. Error of the Estimate \\
\hline 1 &, $517^{\text {a }}$ &, 268 &, 260 & 4,00497 \\
\hline a. Predictors: (Constant), TOTALX & &
\end{tabular}

Sumber: Data diolah, 2020 
Nilai $R$ Square pada koefisien determinasi sebesar 0,268. Hal ini berarti variabel Efektivitas Pelayanan dipengaruhi oleh variabel Antrian sebesar 26,8\%. Hasil uji hipotesis dilakukan melalui uji signifikan $\mathrm{T}$ untuk mengetahui apakah hipotesis diterima atau ditolak. Hasil uji signifikan T disajikan pada tabel berikut:

Tabel 8. Uji Signifikan $T$

Coefficients $^{\mathbf{a}}$

\begin{tabular}{|c|c|c|c|c|c|}
\hline \multirow[b]{2}{*}{ Model } & \multicolumn{2}{|c|}{ Unstandardized Coefficients } & \multirow{2}{*}{$\frac{\text { Standardized Coefficients }}{\text { Beta }}$} & \multirow{2}{*}{$\mathrm{T}$} & \multirow{2}{*}{ Sig. } \\
\hline & B & Std. Error & & & \\
\hline (Constant) & 37,729 & 4,343 & & 8,688 & ,000 \\
\hline TOTALX & ,418 & ,070 & ,517 & 5,983 & 000 \\
\hline
\end{tabular}

Sumber: Data diolah, 2020

Hasil uji signifikan $\mathrm{T}$ menunjukkan hasil t hitung lebih besar dari nilai t tabel yaitu 1,6605. Signifikansi dari uji T pada penelitian ini menunjukkan angka di bawah 0,05, maka dapat disimpulkan bahwa ada pengaruh antara efektivitas pelayanan dengan antrian. Hal ini berarti Ha diterima dan Ho ditolak.

\section{Pembahasan}

Penelitian ini membahas tentang bagaimana pengaruh efektivitas pelayanan dalam menangani antrian pembelian tiket. Secara umum, kelebihan dari penelitian ini adalah mengetahui secara pasti apa yang menjadi kendala dalam penanganan antrian dengan menggunakan C-VIM. Membandingkan dengan penelitian sebelumnya, kekurangan dalam penelitian ini adalah tidak membahas secara lebih luas terkait pengadaan C-VIM dari sudut pandang PT KCI. Penelitian ini juga terbatas hanya dilakukan di stasiun Bekasi.

Tujuan utama dilakukan penelitian ini adalah untuk mengetahui bagaimana efektivitas penggunaan Commuter Line Ticket Vending Machine (C-VIM) dalam menangani antrian pembelian tiket di stasiun Bekasi. Secara umum, proses pengolahan data pada penelitian ini menunjukkan hasil yang baik. Hal ini dilihat dari hasil uji linearitas menunjukkan nilai Deviation from Linearity sebesar 0,100 di mana hasil ini lebih besar dari 0,05, maka dapat disimpulkan bahwa antara variabel efektivitas pelayanan dengan variabel Antrian memiliki hubungan yang linear.

Uji koefisien korelasi menunjukkan nilai Pearson Correlation sebesar 0,517. Jika diinterpretasikan, hasil uji koefisien korelasi menunjukkan bahwa antara variabel efektivitas pelayanan dengan variabel antrian memiliki hubungan korelasi yang sedang.

Ditemukan nilai $R$ Square adalah sebesar 0,268, hasil ini membuktikan bahwa variabel antrian mampu mempengaruhi sebesar $26,8 \%$ terhadap variabel efektivitas pelayanan. Pada uji signifikan T digunakan sebagai penentuan apakah hipotesis diterima atau ditolak. Adapun Signifikansi dari uji T pada penelitian ini menunjukkan angka 0,000 atau dibawah 0,05 . Nilai ini berarti adanya pengaruh antara efektivitas pelayanan dengan antrian. Hasil ini menunjukkan bahwa Ha diterima dan Ho ditolak.

Membandingkan dengan hasil penelitian sebelumnya, penelitian Nafisah Yuliani pada 2018 $\underline{\text { menunjukkan hasil bahwa keberadaan C-VIM belum sesuai harapan. Berdasarkan hasil penelitian }}$ 
Firdha Fany Ardi pada 2016 menunjukkan bahwa adanya pengaruh positif dan signifikan terhadap penggunaan C-VIM. Kedua penelitian ini sejalan dengan penelitian yang dilakukan saat ini, yaitu antara indikator antrian dengan efektivitas C-VIM memiliki pengaruh yang signifikan dan positif, namun pada pelaksanaannya belum maksimal, sehingga perlu dilakukan beberapa perbaikan seperti kualitas mesin, kesigapan petugas, maupun kelengkapan informasi.

\section{KESIMPULAN DAN SARAN}

\section{Kesimpulan}

Penelitian ini merupakan penelitian kuantitatif yang menguji bagaimana pengaruh antara Efektivitas Pelayanan dengan Antrian dalam proses penggunaan Commuter Line Ticket Vending Machine (C-VIM) di Stasiun Bekasi. Berdasarkan hasil perhitungan dalam penelitian ini, ditemukan hasil bahwa variabel Efektivitas Pelayanan berpengaruh secara signifikan dan positif.

Tujuan utama dikeluarkannya Commuter Line Ticket Vending Machine (C-VIM) adalah untuk mempermudah masyarakat dalam melakukan pembelian tiket KRL. C-VIM diharapkan dapat menjadi pilihan alternatif pengguna KRL dalam pembelian tiket agar tidak terpaku pada loket konvensional, nantinya C-VIM akan diberlakukan di semua stasiun KRL dan diharapkan dapat menggantikan peran loket konvensional. Tujuan lain dikeluarkannya C-VIM juga sebagai bentuk pengembangan dari PT KCI untuk mengikuti tren terbaru yaitu Self Service.

Membandingkan antara tujuan PT KCI dengan hasil kuesioner dalam penelitian ini, menunjukkan bahwa responden merasa bahwa C-VIM sudah berfungsi secara optimal. C-VIM dinilai mampu menghasilkan output yang lebih cepat sehingga dapat diterima oleh responden untuk segala kalangan, namun, perlu dilakukan beberapa perbaikan seperti kesiapan mesin, kecepatan, hingga penyediaan petugas guna meningkatkan efektivitas penggunaan. Hal ini membuat responden menyimpulkan bahwa Commuter Line Ticket Vending Machine (C-VIM) mampu menjawab kebutuhan pelanggan, namun masih diperlukan beberapa perbaikan karena hasil penelitian menunjukkan bahwa responden menginginkan pelayanan yang cepat, praktis, dan mudah. Melihat hasil pengolahan data yang ada, dapat disimpulkan bahwa adanya pengaruh antara efektivitas pelayanan dengan antrian. Hal ini berarti Ha diterima dan Ho ditolak.

\section{Saran}

Berdasarkan hasil penelitian ini, efektivitas pelayanan dalam menangani antrian pembelian tiket di Stasiun Bekasi pada saat ini sudah cukup baik. Hal ini ditunjukkan dengan pengaruh yang positif antara kedua variabel, namun, melihat angka pengaruh yang masih rendah, tentu diperlukan beberapa evaluasi demi meningkatkan kualitas efektivitas pelayanan dalam menangani antrian pembelian tiket.

Commuter Line Ticket Vending Machine (C-VIM) dianggap sudah berfungsi optimal sebagaimana tujuannya, namun hal ini belum sepenuhnya dapat menjawab kebutuhan konsumen. Sistem Self Service nyatanya dianggap tidak lebih praktis dibandingkan pelayanan loket konvensional. 
Rahma, Y. \& Mariam, I.(2021). Analisis Efektivitas Commuter Line Ticket Vending Machine ....

Hal ini secara umum turut berpengaruh dalam panjangnya antrian. Melihat kondisi tersebut, penulis menyarankan untuk melakukan pengecekan mesin secara berkala untuk menghindari error system, penempatan petugas untuk mengatur antrian agar tertib terutama ketika jam sibuk, memperbaiki sistem keluar masuk uang dan tidak membatasi pecahan mata uang dalam pembelian tiket, menambah jumlah mesin, hingga melakukan sosialisasi ulang atau penempatan petunjuk penggunaan agar pengguna KRL dapat lebih memahami cara penggunaan Commuter Line Ticket Vending Machine (C-VIM). 


\section{DAFTAR PUSTAKA}

Masruri. (2014). Analisis Efektifitas Program Nasional ( Studi Kasus Pada Kecamatan Bunyu Kabupaten Bulungan tahun 2010 ). Journal of Governance and Public Policy. Universitas Muhammadiyah Yogyakarta

Sinambela, L. P. (2011). Reformasi Pelayanan Publik. Jakarta: PT. Bumi Aksara.

Statistik, B. P. (2019). Jumlah Penumpang Kereta Api, 2006-2020 (Ribu Orang). Badan Pusat Statistik. https://www.bps.go.id/linkTableDinamis/view/id/815

Umam, K. (2012). Manajemen Organisasi. Bandung: Pustaka Setia.

Widayanti, W. (2019). Sekilas PT Kereta Commuter Indonesia. https://krl.co.id 